\title{
$\operatorname{arCOS} D E S I G N$
}

\section{Design Anthropology e o processo de design: experiência e cocriação no projeto, produção e uso}

Raquel Ponte (UFRJ, Brasil)

raquelponte@gmail.com

Av. Pedro Calmon, 550, Cidade Universitária

Rio de Janeiro - RJ, CEP: 21.941-901

Marcos Martins (UERJ, Brasil)

marc.a.martins@gmail.com

Lucy Niemeyer (UERJ, Brasil)

lucy.niemeyer@gmail.com 


\title{
Design Anthropology e o processo de design: experiência e cocriação no projeto, produção e uso
}

Resumo: Associa-se comumente o design ao projeto e à criatividade, sendo apartado da materialização e do uso dos objetos. Vê-se a produção como mera execução mecânica, e o uso, consumo passivo. Este artigo identifica duas dicotomias (design vs. produção e design vs. uso), que um novo campo emergente Design Anthropology - visa questionar. O objetivo é mostrar como a criatividade não cessa na ideação e como há outros criadores envolvidos, além do designer, nesse processo que inclui a experiência e nunca está inteiramente acabado.

Palavras-chave: Design Anthropology, criatividade, produção, uso.

\section{Design Anthropology and design process: experience and co-creation in projects, production and use}

\begin{abstract}
Design is commonly associated with project and creativity, being disconnected from materialization and the use of objects. Production is seen as mere mechanical execution, and use, passive consumption. This article identifies two dichotomies (design vs. production, and design vs. use), which a new emerging field - Design Anthropology - aims to question. The goal is to show how creativity does not stop at forethought and how there are other creators involved, besides the designer, in this process that includes experience and is never entirely finished.
\end{abstract}

Key words: Design Anthropology, creativity, production, use. 


\section{Introdução}

Segundo o International Council of Societies of Industrial Design (ICSID), "o design consiste em uma atividade criativa que visa estabelecer as qualidades multifacetadas dos objetos, processos, serviços e seus sistemas em seu ciclo de vida completo"1. Também Richard Buchanan (1995) deixa evidente ser a atividade criativa parte inseparável do design quando afirma que esse campo não deve ser visto como uma ciência da descoberta, como são as ciências da natureza, pois seu objeto não é dado, mas uma ciência da invenção, pois ele é indeterminado, sendo construído por meio de atividades de planejamento. Porém, como identifica o próprio Buchanan, o design sempre foi associado à etapa projetual da produção, uma vez que, nascido com a revolução industrial, acompanhou o processo de especialização, que apartou a ideação do fazer, antes indissociáveis em uma só pessoa: $\mathrm{o}$ artesão. O designer, portanto, seria o responsável pela criação de uma ideia - um projeto - a ser materializada, por um executor, em um produto ou serviço, que, posteriormente, seria utilizado por um usuário. A partir desse entendimento do design, pode-se depreender a existência de duas dicotomias implícitas: design vs. produção e design vs. uso. Nesse sentido, o processo criativo ater-se-ia ao planejamento, sendo a produção uma mera execução de uma ideia preconcebida, e o uso, apenas um consumo passivo.

O objetivo deste artigo é apresentar uma nova proposta de compreensão do design surgida a partir da virada deste milênio, a qual altera tais dicotomias, na medida em que entende o design como um processo nunca acabado, em que a criatividade não cessa de atuar. Essa nova proposta consiste no Design Anthropology, um campo emergente híbrido, que conjuga duas disciplinas, aproveitando suas potencialidades, oferecendo uma nova visão sobre o processo produtivo e sobre o uso dos produtos e serviços de design.

Neste artigo, veremos primeiramente como essas duas dicotomias foram construídas e sedimentadas para, então, conhecermos a proposta do Design Anthropology, que se utiliza da experiência presente com os participantes do projeto (todos os stakeholders) para fazer proposições que podem transformar o próprio usuário. Assim, este último se torna ativo, passando a cocriador, por meio de seu engajamento, e a ideação e o fazer voltam a ser imbricados no processo criativo.

1. "Design is a creative activity whose aim is to establish the multi-faceted qualities of objects, processes, services and their systems in whole life cycles. [...]" [tradução livre da autora]. Em Definition of Design, disponível em http://www.icsid.org/about/about/articles31.htm. Consultado em 22 jan 2013. 


\section{As duas dicotomias no design}

Buchanan remonta à Grécia antiga para abordar o que ele nomeia de forethought (previsão) e making (fazer), recorrendo a Aristóteles. Para o filósofo, seria próprio do homem a capacidade do fazer e esse fazer incluiria um elemento de previsão, de planejamento. Segundo Buchanan (1995, p.31), "o elemento de antecipação no fazer é um tipo de arte universal, [...] uma arte 'arquitetônica' ou 'mestre', preocupada com descoberta e invenção, argumento e planejamento, e os propósitos ou fins que norteiam as atividades das artes e ofícios." ${ }^{2}$ Mesmo identificando os dois elementos, Aristóteles não distinguia uma separação entre eles: eram partes de uma mesma unidade, uma vez que os produtores e artesãos eram responsáveis por todas as etapas produtivas até então.

A ruptura entre os dois conceitos iniciou-se no Renascimento, a partir de uma combinação das ideias aristotélicas e platônicas. O projeto afastou-se do fazer, assim como o ideal, do real. Esse movimento tornou-se claro na arquitetura. Se até a Idade Média não havia uma divisão radical entre projeto e construção - o primeiro seria o aspecto abstrato e o segundo, o aspecto material da execução - (INGOLD, 2013, p.56), no Renascimento, assumiu-se que a tarefa do arquiteto consistia na definição das formas da construção, enquanto a do construtor seria unir forma e material (INGOLD, 2012). Um exemplo dessa nova visão foi claramente explicitado por Leon Battista Alberti (1404-1472) no prefácio de seu livro Ten books - citado em Ingold (2013, p.49-50) -, no qual define o campo da arquitetura: o carpinteiro passou a ver visto como instrumento do arquiteto. Desta maneira, podemos perceber que o trabalho intelectual tornou-se mais valorizado que o manual, já que, sob influência dos conceitos platônicos, passou-se a acreditar que o mundo das ideias seria a perfeição, enquanto o mundo material, mera imitação imperfeita.

O desenvolvimento de uma nova visão de mundo, moderna, baseada na crença da possibilidade de se compreenderem todos os fenômenos por meio da ciência e da apreensão do universo pela criação de representações abstratas em forma de leis universais, levou também à criação de um instrumento de representação visual do tridimensional no plano: a perspectiva (PANOFSKY, 1997). O pintor e arquiteto italiano Giorgio Vasari (1511-1574) escreveu que disegno "[...] nada mais é que uma expressão visual e um esclarecimento deste conceito que uma pessoa tem no intelecto, e aquilo que se imagina na mente

2. "Forethought in making is a kind of universal art, [...] an 'architectonic' or 'master' art, concerned with discovery and invention, argument and planning, and the purposes or ends that guide the activities of the subordinate arts and crafts" [tradução livre da autora]. 
e que constrói a ideia”3 (apud INGOLD, 2013, p.51). Desta forma, as linhas da perspectiva que delineavam o espaço eram intangíveis, pois consistiam em algo puramente conceitual e racional, e era essa racionalidade abstrata ideal, acreditavam, o que originava as coisas existentes.

Hallam e Ingold (2007, p.5) afirmam que está enraizada no pensamento moderno a crença de que tudo que é criado possui um projeto anterior, e de que, seja na construção de um edifício, seja na criação de um ser vivo ${ }^{4}$, há sempre uma forma virtual preexistente que gera a materialidade - um pensamento idealista em essência. E o design incorporou essa ideia, pois pode ser considerado um filho do moderno. A criatividade é então deslocada para o planejamento, para a ideação, reduzindo o fazer a mera implementação do projeto preexistente. E o designer passa a ser o único responsável criativo pelo projeto.

Se já há uma dicotomia entre design e produção, evidentemente deve existir entre design e uso, uma vez que este último aparece como uma etapa posterior à materialização do produto, sendo uma finalidade para o projeto sob uma lógica de mercado. Ainda que os produtos de design sempre tenham sido projetados para um usuário consumir, a inclusão deste último no projeto de design (user-centered design) é recente, datando da década de 1980 (sANDERs, 2001). Essa dicotomia decorre do fato de a produção capitalista do início do século xx ter como foco a produção. Como havia escassez de bens no mercado, a indústria ocupava-se apenas em aumentar a produtividade, sem se preocupar se, na realidade, os objetos atendiam às necessidades e aos desejos do consumidor. O modelo fordista foi um sucesso nas primeiras décadas do século xx, pois toda a produção escoava rapidamente, uma vez que existia um público ávido por produtos industrializados.

Porém, aos poucos, com a saturação do mercado e o contínuo crescimento da produção, sentiu-se a necessidade de se repensar o processo de design, incluindo o usuário, pois conhecendo-o, haveria a possibilidade de projetar bens que realmente atendessem a seus interesses. Esse entendimento de design e uso como uma dicotomia, segundo Redström (apud GunN e DonOvan, 2012, p.2), pode, portanto, ser visto como consequência da forma de produção e consumo de massa que se estabeleceu após a revolução industrial. Por isso não deve ser considerada como condição básica do design, mas como algo construído e como estado de transição de uma concepção do design.

3. "[...] is nothing but a visual expression and clarification of that concept which one has in the intellect, and that which one imagines in the mind and builds up the idea" [tradução livre da autora].

4. Ingold (2012) cita o exemplo do teólogo e filósofo britânico William Paley (século XVIII). Sempre comparando os seres vivos aos artefatos (morcegos a relógios), ele afirmava que a complexidade dos animais deixava clara a existência de um criador inteligente. Assim como um relojoeiro concebe e cria um relógio, também haveria um designer para os seres vivos: Deus. Essa inteligência superior criaria o organismo, mas os demais, suas cópias, seriam frutos de mera execução mecânica. Logo não haveria design sem designer, isto é, sem a presença de uma mente e de uma inteligência. 
As ideias de Karl Marx mostram-se aqui como um exemplo relevante para se pensar nessas duas dicotomias. Ele escreve que o processo de trabalho humano, diferentemente daquele do animal "[...] termina na criação de algo que, quando o processo começou, já existia... de uma forma ideal5" (apud INGold, 2011). Fica evidente que Marx também concordava com uma ideia preconcebida que determinava sua materialização, porém, curiosamente, ele entendia haver algo que fomentava essa imagem ideal, algo anterior à ideia: o consumo. O consumo era então considerado como fim, mas também como o impulsionador do processo produtivo. Assim, seria criando expectativas sobre como as coisas devem ser conformadas que se motivaria a criação de ideias e sua produção. O que ele acaba por propor é uma circularidade, em que consumo evoca produção, que evoca consumo, ad infinitum, eliminando a possibilidade de se determinar qual o precedente nesse movimento contínuo. A produção e o consumo, para ele, são partes de um mesmo processo.

A mudança de foco de pontos estanques, de finalidades e inícios, para uma visão de processo contínuo é a proposta de Tim Ingold. Seu trabalho surge como uma grande referência para aqueles pesquisadores que vêm se alinhando com um novo campo emergente de estudo: o Design Anthropology. A partir de suas ideias na antropologia e da relação estabelecida entre antropologia e design pelo Design Anthropology, podemos utilizar seus conceitos para alterar nosso entendimento do design, rompendo com as dicotomias apresentadas e compreendendo projeto, produção e uso como partes de um processo maior, em que a criatividade não cessa nunca de operar.

\section{Design Anthropology}

A partir da década de 1970, o design e as ciências sociais começaram a dialogar mais efetivamente. Até a inserção da etnografia no design, o campo mais largamente utilizado como meio de conhecimento do usuário era a psicologia cognitiva. Mas também as ferramentas de pesquisa de marketing contribuíam para identificar padrões estatísticos nas práticas cotidianas dos consumidores. Porém essas ferramentas suscitavam poucos insights na compreensão de modelos culturais locais e de ideologias por trás da visão desses consumidores acerca dos produtos (WASSON, 2010). Os designers passaram a perceber que os métodos etnográficos, utilizados pela antropologia, podiam ser empregados no design como forma de levantar informações mais precisas sobre as necessidades e as experiências dos usuários e sobre os contextos de uso dos

5. "[...] ends in the creation of something which, when the process began, already existed ... in an ideal form" [tradução livre da autora]. 
produtos (отто \& SMITH, 2013, p.2), porque não se baseavam nas informações verbalizadas pelos usuários, mas buscavam um conhecimento observável, tácito e latente (sANDERs, 2002, p.3).

O design, afirma Wasson, sempre foi visto como uma potencial ferramenta de vendas dentro da lógica capitalista e, portanto, não é estranho que a incorporação da etnografia como parte da pesquisa para desenvolvimento de projeto também tenha tido como objetivo final o incremento dos lucros. Nesse sentido, a antropologia era utilizada para o design como uma ferramenta, um instrumental para coleta de dados. Porém, mais recentemente, na virada do milênio (HALSE, 2008, p.7), o Design Anthropology emerge como um campo em que ambas as disciplinas estão alicerçadas em um mesmo patamar, oferecendo uma visão mais crítica dos processos, sem que a antropologia cumpra apenas um papel meramente instrumental. Para Gunn e Donovan (2012), o design e a antropologia podem beneficiar-se mutuamente, pois cada disciplina tem sua própria metodologia e identidade. A antropologia contribui para o Design Anthropology com seu entendimento processual da realidade, e o design, com o gerenciamento de não apenas pessoas, mas de uma multiplicidade de materiais, ações, performances etc.

O Design Anthropology, como uma abordagem híbrida, “[...] envolve formas intervencionistas de pesquisa e projeto em campo, trabalho realizado através de ciclos iterativos de reflexão e ação, combinando procedimentos, métodos e ferramentas das duas áreas, design e antropologia" (ANASTASSAKIS \& KUSCHNIR, 2014, p.7). Esse novo campo também se utiliza de vários métodos de colaboração entre os diversos participantes (stakeholders) envolvidos, como veremos mais adiante. Gunn e Donovan (2012) afirmam, ainda, que a prática do Design Anthropology busca instigar diferentes formas de projeto em situações emergentes, comprometendo-se com pessoas e lugares em que o problema nem sempre é dado, saindo da concepção de um design problem-oriented. Mostra-se importante ressaltar o crescimento desse campo tão recente, que conta atualmente com dois programas de mestrado: um na Escócia e outro na Austrália (ANASTASSAKIs, 2013, p.180).

Veremos então como a proposta do Design Anthropology pode romper com as dicotomias design (forethought) vs. produção (making) e design vs. uso, focando na experiência e na colaboração do usuário, entre outros agentes do processo. 


\section{A criatividade no making}

Ingold (2012), tratando da questão da dicotomia projeto/criação vs. produção/execução, toma um exemplo da arquitetura, já citada anteriormente por ser uma das primeiras áreas onde se encontra esse pensamento moderno dicotômico. Para ele, enquanto tendemos a idealizar a criação como uma preconcepção anterior à materialização mecânica, o que ocorre na prática mostra que a o processo criativo ocorre de outra forma. A catedral de Chartres na França não tem seu projeto conhecido e, na realidade, não se sabe ao certo se sequer houve um. Muitos foram os cocriadores da catedral ao longo dos anos, entre eles os próprios construtores, carpinteiros e mestres de obra, devendo sua forma final à acumulação do trabalho de várias pessoas. Cada intervenção e cada resolução de problemas ao longo do fazer contribuíram para seu projeto final. O que essa ideia traz de interessante é que o design passa a não ser mais apenas uma etapa inicial imaterial do projeto, mas uma consequência das alterações e criações ao longo do processo de feitura, unindo planejamento e execução, uma vez que o projeto sozinho não materializa o objeto.

Ian Ewart, em Designing by doing: building bridges in the highlands of Borneo (2013), afirma que o mesmo se aplica à engenharia: na figura de um engenheiro que se tornou antropólogo e que atuou na construção de pontes, escreve que não consegue conceber o processo de design apartado da produção. Ele argumenta que há algumas abordagens da engenharia que partem do preceito de que a produção é uma infeliz consequência do design ou serva do uso (EWART, 2013, p.86) e apresenta então duas etnografias de duas construções de ponte no Bornéu: uma dentro do modelo tradicional design vs. produção, em que o controle da primeira se faz na segunda; e outra, mais intuitiva, com mecanismos mais fracos de controle, em que as contigências surgidas iam sendo resolvidas por meio de improvisações. A segunda ofereceu um resultado mais rico que a primeira, que se manteve dentro dos planos inicialmente desejados.

Hallam e Ingold (2007) apresentam a ideia de que a improvisação é uma forma de criatividade diferente da inovação, porque esta última foca no objeto, enquanto a primeira foca nos processos. Eles mostram que improvisar é responder às contingências da vida. Para os autores, o mundo está sempre se fazendo em um processo crescente, não sendo determinístico. Dessa forma, o projeto ideal nem sempre pode antecipar todas as questões, pois é na experiência, no momento da materialização, que contingências não previstas devem ser contornadas. E podemos dizer que esses "desvios" são respostas criativas incorporadas ao projeto, ou melhor, são o próprio projeto, cuja concepção ainda não terminou na primeira fase de ideação. 
Olhando o design sob esse prima, percebe-se que o mesmo ocorre na materialização dos produtos. Por exemplo: é comum, na vivência dos comunicadores visuais e produtores gráficos, alterar o projeto (forethought) no momento da produção (making): uma nova escolha de papel para responder melhor a um tipo de tinta ou a um processo de impressão; uma escolha de um acabamento não pensado previamente para preservar melhor o material; uma colocação de uma quinta cor para evitar distorções cromáticas causadas pela variação natural que o processo de produção ocasiona. Em alguns casos, a concepção do projeto ocorre conjuntamente com os profissionais da indústria quando muitas variáveis se reúnem em um mesmo trabalho. Em certos projetos de alta complexidade de materialização, soluções vão sendo encontradas ao longo do fazer à medida que etapas vão sendo vencidas. Às vezes, pode haver um esboço da ideia inicial que seja flexível a mudanças, mas não um pré-projeto definitivo e controlado, que deveria ser meramente copiado 6 .

Por isso, os profissionais gráficos, não considerados pelo mercado como criadores em essência, lidam criativamente com os problemas que surgem, improvisando soluções e adequando o projeto. É na produção gráfica, no caso da comunicação visual, que variáveis não esperadas devem ser resolvidas, sendo essas resoluções interferências criativas no design. O projeto, assim, pode acabar mudando ao longo do processo de execução. Como Edward Bruner observa (apud HALLAM \& INGOLD, 2007, p.2), as pessoas improvisam "[...] não porque estão operando de dentro de um conjunto de convenções, mas porque nenhum sistemas de códigos, regras e normas pode antecipar todas as circunstâncias".

O que o Design Anthropology traz de reflexão é a ideia do design não como algo preconcebido, preexistente, mas como algo que se modifica no fazer. Pode-se partir de um conceito inicial na etapa de ideação, mas a impossibilidade de controle total em um mundo em crescimento pode trazer a necessidade de se rever esse conceito várias vezes. Assim, em vez de uma ideia estanque que é meramente executada, o que se deseja transmitir é uma concepção de uma continuidade de ideias em transformação, imbricadas, com idas e vindas, que vão sendo moldadas pelo fazer, de acordo com as contingências que surgem. Como afirma Ingold (2013, p.21), "eu quero pensar no making [..] como um processo de crescimento. Isto é colocar o maker desde o início como um participante no meio de um mundo de materiais ativos"”.

6. Essas observações foram realizadas ao longo de minha prática profissional como designer e produtora gráfica, mostrando que a análise da experiência pode ser útil como método de levantamento de dados e questionamento de teorias desvinculadas da realidade.

7. "I want to think of making [..] as a process of growth. This is to place the maker from the outset as a participant in amongst a world of active materials" [tradução livre da autora]. 
Quando uma ideia é revisitada, ela é transformada e enriquecida pelas memórias e experiências novas. Quando partilhada, as particularidades das experiências individuais as enriquecem. Apenas quando olhamos para trás procurando os antecedentes das inovações é que as ideias se parecem com criações espontâneas de uma mente isolada em um corpo, desintegrada dessas linhas e caminhos que a conformaram (hallam \& INGOLD, 2007). Por isso, as criações no design parecem-se apenas como pertencentes aos mentores intelectuais: os designers. Mas na realidade, o processo de design configura-se como uma interlocução entre diversos participantes.

\section{A experiência e o engajamento dos agentes}

Para o Design Anthropology, o processo de criação de soluções para problemas nem sempre dados consiste em uma atividade compartilhada. Como afirma Halse (2008, p.4), em pensamento concordante ao de Buchanan, quando declara que o design é uma ciência da invenção, com o Design Anthropology "o material empírico foi gerado - ele não estava lá fora independente de mim mesmo, o que implicaria uma ontologia realista. E ele não esperou por mim para ser descoberto, o que implicaria uma epistemologia positivista. Ele foi coproduzido $[\ldots]^{8}$ ".

Uma das sugestões desse novo campo é a substituição de protótipos por "provótipos" (de provotypes, um neologismo jocoso criado a partir do termo provocation), o que apontaria para uma mudança de perspectiva requirement-oriented para uma exploration-oriented (Donovan e Gunn, 2012). O protótipo, dentro da primeira perspectiva, utiliza-se da experiência do usuário com o objeto com a intenção de gerar um fechamento do seu projeto (isto é, o foco final é a coisa projetada) e sempre foi considerado importante no design centrado no usuário, uma vez que identifica as suas necessidades a fim de desenvolver os conceitos de design. Já os provótipos (perspectiva exploration-oriented) são entendidos como design-thinking enablers, não sendo apenas ferramentas para avaliação dos resultados de design. Nesse caso os provótipos podem ser usados como catalisadores no engajamento de usuários no jogo com a linguagem do design. Os provótipos são utilizados, portanto, como mediadores que provocam reflexão sobre práticas existentes (MORGENSEN apud GUNN \& DONOVAN, 2012, p.123).

Dessa maneira, a experiência seria trazida para dentro do processo de design na medida em que os provótipos podem instigar discussões sobre as

8. "the empirical material has been generated - it was not out there independent of myself, implying a realist ontology. And it did not wait for me to discover it, implying a positivist epistemology. It was coproduced [...]" [tradução livre da autora]. 
práticas por meio da prática. Pela confluência de diferentes narrativas envolvidas nos processos materializadas em um provótipo, os agentes envolvidos chegam a uma reflexão sobre as questões levantadas pelos pesquisadores na busca por soluções para problemas não dados, mas latentes. Por isso os workshops são tidos como experiência importantes no Design Anthropology para buscar essa reflexão sobre os provótipos. Gunn e Donovan (2012, p.129) citam como exemplo o projeto "Indoor Climate and Quality of Life", desenvolvido pela SPIRE ${ }^{9}$ com diferentes parceiros (universidades, empresas, funcionários de jardins de infância, escritórios e casas), cujo objetivo era ampliar os horizontes da imaginação em relação a esse tema e aprender a pensar de forma mais aberta e integrada do que especialistas fariam. Os protótipos utilizados não eram considerados objetos durante os workshops, mas seu valor dependia das relações geradas no processo do fazer (GUNN \& DONOvAN, 2012, p.125). Isso implica uma reformulação do papel do designer, que deixa de ser o criador único de um projeto de design e passa a ser um dream-catcher, na visão de Gunn e Donovan, abrindo caminhos para a improvisação.

Um outro procedimento frequente consiste na formulação de performances, na criação de cenários, utilizando-se atores para encenar situações. A performance torna-se um método de mudança e reflexão cultural (HALSE, 2008, p.85), ao liberar a imaginação dos agentes, improvisando situações e ações e criando futuros possíveis. Como escreve Halse (2008, p.80),

Podemos melhorar a eficácia do processo de design, concebendo-o como uma performance? "[...] Assumir pró-ativamente a ideia de que tudo em princípio é incerto e reversível implica, em termos de design, um estímulo para considerar o processo de concepção um esforço consciente para promulgar modos particulares da realidade e as inquietações das pessoas sobre eles. ${ }^{10}$

Como podemos ver, a ênfase no Design Anthropology é dada ao processo e não aos fins, ainda que se deseje chegar a uma solução em forma de produto ou serviço. Essa visão de mundo relaciona-se ao pensamento de Ingold (2011),

\footnotetext{
9. SPIRE é um centro de pesquisa da Mads Clausen Institute (Dinamarca) focada em inovação, que trabalha por meio da colaboração entre seus pesquisadores e a indústria local. Visa desenvolver novos produtos e emprega, para isso, engenheiros, antropólogos, linguistas, designers, pesquisadores de marketing, consultores e atores. É um importante centro de estudo em Design Anthropology. Mais informações podem ser obtidas em http://www.sdu.dk/en/Om_SDU/Institutter_centre/C_SPIRE.aspx.

10. "Could we improve the efficacy of the design process by conceiving it as a performance?" [...] To pro-actively take up the idea that everything in principle is uncertain and reversible, implies, in terms of design, an encouragement to consider the design process a conscious effort to enact particular modes of reality and people's concerns about them." [tradução livre da autora].
} 
que busca uma percepção menos "transitiva" do processo, em que se coloca todo o foco da ação em um objeto a ser atingido. Pensando "intransitivamente", o autor enfatiza o processo contínuo sobre a forma final, dispensando a necessidade de haver uma representação a priori, como condição indispensável para a produção, para a obtenção de um fim. Para o Design Anthropology, a experiência promovida - esse processo intransitivo - é um meio de se atingir o engajamento dos agentes para uma real transformação por meio do design.

Se temos, por meio dessas práticas participativas, uma ideia de cocriação dos diferentes agentes no processo de design, transformando a concepção mais difundida do designer-criador, Gunn e Donovan (2002) vão mais adiante: afirmam ser o usuário também criativo no uso dos produtos e serviços. Para eles, as pessoas geralmente usam os objetos para além do projeto do designer, o que sugere que elas interferem nos produtos e sistemas durante o processo do consumo. Por isso o projeto não deve ser fechado, mas deve permitir as improvisações da vida, uma vez que o uso passa a ser uma forma de design. O usuário passivo, desta forma, passa a ser um skilled practitioner (GUNN \& DONOVAN, 2012, p.2) e se transforma no processo de design.

A reconceituação dos usuários como sendo (ou que tendo a possibilidade de se tornar) skilled practitioners de produtos e sistemas exige formas diferentes de conceber, projetar e fabricar coisas que permitam que as pessoas desenvolvam habilidades ao longo de sua vida em que competências são enriquecidas em vez de erodidas ${ }^{11}$ " (GUNN \& DONOVAn, 2012, p.2).

\section{Conclusão}

Como vimos ao longo deste artigo, o campo do Design Anthropology, unindo as características e metodologias de dois campos aparentemente tão separados, questiona a separação entre design e produção e entre design e uso, compreendendo o processo de design como uma continuidade, que engloba todos esses aspectos. A criatividade, portanto, não fica restrita à fase de ideação (forethought), estendendo-se à produção (making) e ao uso. Para o Design Anthropology, os produtores (makers) e outros agentes envolvidos passam a cocriadores, questionando o papel de um designer único, que concebe uma

11. "Re-conceptualization of users as being (or having the possibility of becoming) skilled practitioners of products and systems requires different ways of conceiving of, designing and making things that allows for people to develop skills over their lifetime whereby skills are enriched rather than eroded." [tradução livre da autora]. 
ideia completa em si mesma anterior à execução de um produto ou serviço. Como escrevem Gunn e Donovan (2002, p.1), "o processo de design não deve impor um fechamento, mas deve permitir que a vida continue" ${ }^{12}$.

Para isso, esse campo emergente propõe práticas que possibilitem a experiência do compartilhamento da criação para solucionar problemas que, muitas vezes, não são dados. Isto porque a vida é plena de contingências. Provótipos, workshops, criação de cenários, performances - tudo isso favorece as improvisações criativas e geram engajamento dos agentes. Esse engajamento entre pessoas com diferentes formas de conhecimento e de fazeres visa a uma transformação da sociedade e de si próprias por meio do design (GUNN \& DONOVAN, 2012, p.2).

Resta-nos ver, com o desenvolvimento do Design Anthropology, até que ponto essas propostas conseguem de fato alterar o mainstream no design. Hunt (2011, p.41) faz críticas quando escreve que por mais cativantes que sejam esses projetos, é claro que eles não irão causar uma transformação social em larga escala, por serem mais especulativos que intervencionistas. Gunn e Donovan (2012, p.131), no final do projeto da SPIRE sobre climatização indoor e sistemas de controle, também apontam como foi difícil perceber se a participação nos workshops de fato alterou o pensamento das pessoas sobre o design e sobre o uso de produtos. E isto se apresenta como um desafio, porque, diferentemente do Critical Design - proposto pelos designers britânicos Dunne e Raby e constantemente citado na bibliografia sobre Design Anthropology -, que entende apenas serem possíveis a crítica e a transformação afastando suas propostas do mercado (DUNNE \& FIONA, 2013), o Design Anthropology deseja gerar soluções e inovações em produtos e serviços que sejam partilhados com os usuários. Poderemos ver nos próximos anos, com o desenvolvimento e aplicações das práticas nos projetos de design, se a teoria do Design Anthropology conseguirá alterar a experiência e percepção do design.

\section{Referências bibliográficas}

ANASTASSAKIS, Zoy. Laboratório de Design e Antropologia: preâmbulos teóricos e práticos. In: Arcos Design. Rio de Janeiro, v. 7 n. 1, jul 2013, pp. 178-193.

ANASTASSAKIS, Zoy \& KUSCHNIR, Elisa. Trazendo o design de volta à vida: considerações antropologicamente informadas sobre as implicações sociais do design. [no prelo, 2014].

12. "A process of design thus is not to impose closure but to allow for everyday life to carry on" [tradução livre da autora]. 
BICHARD, Jo-Anne; GHEERAWO, Rama. "The Ethnography in Design”. In: CLARKE, Alison J. (Ed.). Design Anthropology. Object culture in the 21st Century. Viena: Springer-Verlag, 2011, p. 9-13.

BUCHANAN, Richard. "Rethoric, Humanism and Design". In: BUCHANAN, Richard; MARGOLIN, Victor (Eds.). Discovering Design. Explorations in Design Studies. Chicago and London: The University of Chicago Press, 1995, p. 23-66.

DUNNE, Anthony \& RABY, Fiona. Speculative everything: design, fiction and social dreaming. Massachusetts: MIT Press, 2013.

EWART, Ian J. "Designing by doing: building bridges in the highlands of Borneo”. In: GUNN, Wendy; OTTO, Ton \& SMITH, Rachel Charlotte (Ed.). Design Anthropology: Theory and Practice. Bloombury, 2013, p. 85-99.

GUNN, Wendy; DONOVAN, Jared. "Design Anthropology: An Introduction". In: GUNN, Wendy; DONOVAN, Jared. (Eds.). Design and Anthropology. London: Ashgate, 2012, p. 1-16.

GUNN, Wendy; DONOVAN, Jared. "Moving from Objects to Possibilities". In: GUNN, Wendy; DONOVAN, Jared. (Eds.). Design and Anthropology. London: Ashgate, 2012, p. 121-134.

HALSE, Joachim. Design Anthropology: Borderland Experiments with Participation, Performance and Situated Intervention. 2008. 193 f. Tese (Doutorado) - IT University of Copenhagen, Copenhagen, 2008.

HUNT, Jamer. "Prototyping the Social: Temporality and Speculative Futures at the Intersection of Design and Culture". In: CLARKE, Alison J. (Ed.). Design Anthropology. Object culture in the 21st Century. Viena: Springer-Verlag, 2011, p. 33-44.

INGOLD, Tim. Anthropology comes to life. In: Being Alive. Essays on Movement, Knowledge and Description. London e New York: Routledge, 2011, p. 3-14.

INGOLD, Tim. "Introduction: The Perception of the User-Producer". In: Design and Anthropology. Burlington: Ashgate, 2012, p. 19-33. 
INGOLD, Tim. Making. Nova Iorque: Routledge, 2013.

KRAUSS, R. E. Fat Chance. In: Perpetual inventory. Cambridge: MIT Press, 2010.

LENSKJOLD, Tau Ulv. "Accounts of a Critical Artefacts Approach to Design Anthropology”. In: Nordic Design Research Conference, 2011. Helsinki: www.nordes.org, 09p.

OTTO, Ton \& SMITH, Rachel Charlotte. "Design Anthropology: a distinct style of knowing”. In: GUNN, Wendy; OTTO, Ton \& SMITH, Rachel Charlotte (Ed.). Design Anthropology: Theory and Practice. Bloombury, 2013, p. 1-29.

PANOFSKY, E. Perspective as symbolic form. New York: Zone Books, [1924-25] 1997.

SANDERS, Elizabeth B. N. From user-centered to participatory design approches. In: FRASCARA, Jorge (Ed.). Design and the Social Sciences: Making Connections. Taylor \& Francis, 2002, p. 1-8.

WASSON, Christina. "Ethnography in the Field of Design". In: Human Organization, vol. 59, n. 4. Society for Applied Anthropology, 2000, p. 377-388. 
Recebido em: $12 / 05 / 2014$

Aceito em: 01/06/2014

\section{Como citar}

PONTE, Raquel; MARTINS, Marcos; NIEMEYER, Lucy. Design Anthropology e o processo de design: experiência e cocriação no projeto, produção e uso. Arcos Design. Rio de Janeiro: PPD ESDI - UERJ. Volume 8 Número 1 Junho 2014. pp. 20-35. Disponível em: [http://www.e-publicacoes.uerj.br/index.php/arcosdesign]

\section{DOI}

http://dx.doi.org/10.12957/arcosdesign.2014.12802

\section{cc) (1) (3)}

A Revista Arcos Design está licenciada sob uma licença Creative Commons Atribuição - Não Comercial - Compartilha Igual 3.0 Não Adaptada. 